\title{
The Separation of Molybdenite from Pyrite and Chalcopyrite
}

\author{
By A. M. Abeidu*, T. S. Kholeif** and A. B. Mostafa*
}

\begin{abstract}
Ideas expressed by some investigators on the regulating action of oxygen (aeration) in the separation of molybdenite from pyrite and chalcopyrite due to their selective oxidation and hence their selective adsorption of collector (ethyl xanthate) were shown to be partially incorrect. Experimentation with oxygen and hydrogen peroxide showed that while the former has only a slight effect on pyrite, the latter has a distinct and a perceptible effect on the adsorbability and floatability indices of all minerals tested. The activating action of oxygen on the flotation of pyrite was shown to be due to the oxidation of ferrous sites to ferric and not due to oxidation of sulphide sites to sulphate, as many investigators claim. The positive increase of electrode potentials of sulphide minerals when dipped in distilled water was shown to be due to the acidity of the latter and not due to their oxidation as most researchers suggest. Leaching chalcopyrite with $\mathrm{H}_{2} \mathrm{SO}_{4}$ solution of $\mathrm{pH} 3$ imparts to it a surface with flotative properties corresponding to that of pyrite, due to the selective leaching of copper sites and the predominance of those of iron. This was successfully used to aid co-depression of chalcopyrite with pyrite. Either $\mathrm{CuSO}_{4}$ or $\mathrm{Na}_{2} \mathrm{SO}_{3}$ could aid the selective separation of molybdenite, whereas their conjoint use gives a complex anion of the type $\mathrm{CuSO}_{4} \mathrm{SO}_{3}^{2-}$, which possesses a tremendous affinity for iron sites over those of molybdenum, whence xanthate (collector) species are selectively adsorbed on the latter leading to the selective flotation and hence separation of molybdenite.
\end{abstract}

(Received July 15, 1978)

\section{Introduction}

Molybdenite $\left(\mathrm{MoS}_{2}\right)$ is the chief source of molybdenum. Quartz veins carrying molybdenite traverse pink granites in the Northeastern Desert of Egypt at Gattar, Gabel um Harbay Wadi Dib. Molybdenite is associated with cassiterte $\left(\mathrm{SnO}_{2}\right)$, wolframite, $(\mathrm{Fe}, \mathrm{Mn})$ $\mathrm{WO}_{4}$, fluorite, $\left(\mathrm{CaF}_{2}\right)$, sulphides such as chalcopyrite $\left(\mathrm{CuFeS}_{2}\right)$ and pyrite $\left(\mathrm{FeS}_{2}\right)$, and other gangue minerals. Of the associated minerals, chalcopyrite and pyrite are the most difficult to separate from molybdenite. The available data in the literature ${ }^{(1) \sim(5)}$ showed that in the collective flotation of copper and molybdenum sluphides from copper-molybdenum ores, the initial flotation rate of molybdenite is lower than that of copper sulphides. Mitrofanov and Kurochkina ${ }^{(1)(2)}$ claimed that flotation with xanthate is an effective method for separation of molybdenite from other sulphides, especially pyrite. Thus, during the

* National Research Centre, Cairo, Egypt.

** Ein Shams University, Cairo, Egypt. process of recleaning no reagents are added and the only effective reagent can be air, oxygendrawn by the chamber impeller to the pulp. In other methods of separation of molybdenite lime, cyanide and sodium sulphide are used for the depression of copper sulphide minerals. In this investigation an attempt was made to study the effect of oxygen (aeration), $\mathrm{Na}_{2} \mathrm{SO}_{3}$, $\mathrm{CuSO}_{4}$ and the mixture of the latter two on the selective flotation of molybdenite with ethyl xanthate as the collector at different pHs.

\section{Experimental Techniques}

Natural crystals of molybdenite, chalcopyrite and pyrite from Gattar Gebel Um Harda and Wadi Dib Districts were used. Microscopic and infrared examination of crystals of these minerals showed that they were clean and free from locked particles and gangue. The method of measuring potentials of these minerals basically resembled that used by Gaudin and Fuerstenau ${ }^{(6)}$; the specific conductance of solutions were obtained from tables in the ready Reference Books of Chemical and Physical 
data $^{(7)(8)}$. Adsorption studies with ethyl xanthate had a high degree of accuracy $( \pm 10 \%)$ and also of sensitivity $(0.02 \%)$. The method is based on analysis in the infrared region of the spectrum with the frequency of $1250-950 \mathrm{~cm}^{-1}$, using the Carl-Zeis UR-10 spectrophotometer. The Hallimond tube and the flotation method used has been described in an earlier paper ${ }^{(9)}$. The pulp density was solid: liquid $=1: 2$ by volume (i.e. $33 \%$ solid).

\section{Results and Discussion}

Figure 1 shows that the electrode potentials of freshly revealed sulphide mineral surfaces are slightly increased when they come in contact with distilled water. However, stirring of water by a mechanical stirrer caused an additional increase of electrode potentials. Preventation of stirring caused a drop of potentials. Also an increase of electrode potentials was noticed when a current of pure oxygen, nitrogen or hydrogen is passed through distilled water. When the current of gas ceased, the electrode potential fell and reached its initial value. Many investigators ${ }^{(6)(10) \sim(21)}$ explain the increase of electrode potentials of sulphide minerals in distilled water by their oxidation

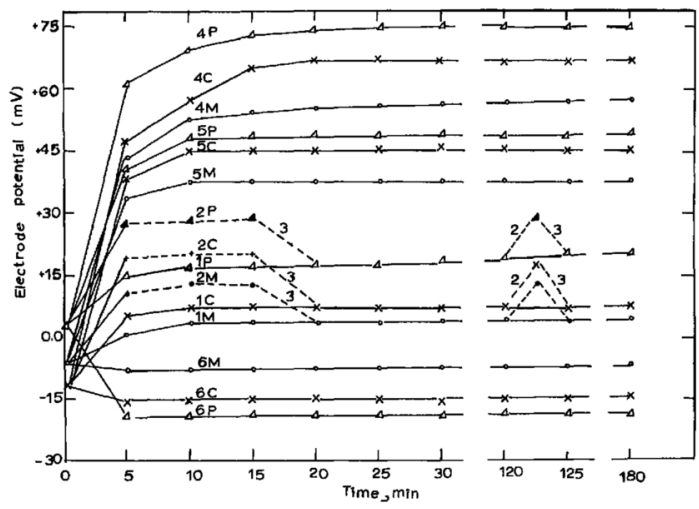

Fig. 1 Electrode potentials of minerals in distilled water as a function of time: (1) without additions, (2) on stirring of water; or during separation of bubbles of oxygen, nitrogen or hydrogen on the surface of the electrode, (3) on preventation of stirring of water; or inhibition of gases (oxygen, nitrogen and hydrogen), (4) on addition of $1 \mathrm{~m} \ell$ of $10 \% \mathrm{H}_{2} \mathrm{O}_{2}$, (5) on addition of $\mathrm{HCl}(\mathrm{pH} 4),(6)$ on addition of $\mathrm{NaOH}$ (pH 7.5). $\mathrm{M}=$ Molybdenite, $\mathrm{C}=$ Chalcopyrite, $\mathbf{P}=$ Pyrite. by oxygen soluble in water. They claim that oxygen is very rapidly sorbed by surfaces of sulphide minerals and chemically interact with them with the formation of the corresponding sulphates. However, Fig. 1 indicates that the acidity of distilled water and its motion as a result of dipping the sulphide electrode are responsible for the positive increase of electrode potentials. This is confirmed by the increase of potential by addition of an acid and by its decrease by addition of an alkali (Fig. 1). Moreover, the addition of hydrogen peroxide markedly increased the positive value of the electrode potential.

Measurements of electrokinetic potentials of minerals investigated (Fig. 2) showed that molybdenite, chalcopyrite and pyrite are isoelectric at $\mathrm{pHs}$ about $5,6.5$ and 7.6, respectively. An increase of $\mathrm{pH}$ increased the negative charge of their surfaces and a decrease of $\mathrm{pH}$ increased the positive charge of their surfaces. An addition of $30 \mathrm{mg} / \ell$ of ethyl xanthate decreased the positive charge of surfaces of chalcopyrite and pyrite and displaced their isoelectric points to $\mathrm{pHs}$ of 5.3 and 6 , respectively. On the other hand, ethyl xanthate had no perceptible effect on the zeta potential of molybdenite on the acid side of the isoelectric point due to the fall of the $\mathrm{pK}_{a}$ of ethyl xanthic acid at a $\mathrm{pH}$ of about $5^{(22)}$. It is useful to indicate that the crystal structure of molybdenite

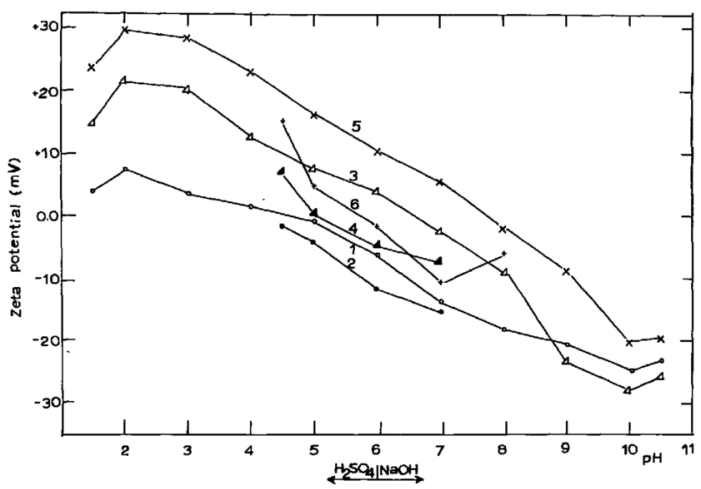

Fig. 2 Zeta potential as a function of $\mathrm{pH}$ : (1) molybdenite without additions, (2) on addition of $30 \mathrm{mg} / \mathrm{l}$ of potassium ethyl xanthate, (3) chalcopyrite without additions, (4) on addition of $30 \mathrm{mg} / \ell$ of potassium ethyl xanthate, (5) pyrite without additions, (6) on addition of $30 \mathrm{mg} / \ell$ of potassium ethyl xanthate. 
is of the flaky type and may be thought of as consisting of stacks of sandwiches of molybdenum sluphide. The distance between the neighbouring sulphur atoms in one slice of a sandwich is $298 \mathrm{pm}$, and that between sulphur atoms in an adjoining sandwich is much greater, namely $366 \mathrm{pm}^{(28)}$. Thus, grinding a crystal of molybdenite gives particles whose faces are composed mainly of sulphide sites. Since the $\mathrm{pK}_{1}$ and $\mathrm{pH}_{2}$ of $\mathrm{H}_{2} \mathrm{~S}$ are 7.05 and 12.90 , respectively ${ }^{(23)}$, the mechanism of attachment of ethyl xanthate to molybdenite surface may be represented as follows:

$$
\begin{array}{r}
\cdots \mathrm{SH}^{+}+\mathrm{ROCSS}^{-}=\cdots \mathrm{SH} \cdot \mathrm{SSCOR} \\
(\mathrm{pH} \mathrm{5-6),} \\
\cdots \mathrm{SH}^{+}+\mathrm{ROCSSH}=\cdots \mathrm{SH} \cdot \mathrm{SHSCOR}^{+} \\
(\mathrm{pH} \mathrm{4-6).}
\end{array}
$$

The symbol'-represents schematically the lattice surface. On the other hand, grinding a crystal of chalcopyrite gives particles whose faces are composed of alternate copper, iron and sulphide sites. Grinding a crystal of pyrite gives particles whose faces are composed of alternate iron and sulphide sites. Since the isoelectric point of ferrous site falls at a $\mathrm{pH}$ of $6.5^{(24)}$, and the isoelectric point of pyrite is noticed at a $\mathrm{pH}$ of 7.6 (Fig. 2) the surface configurations $\cdots \mathrm{FeOH}, \cdots \mathrm{FeOH}^{+}$and $\cdots$ $\mathrm{FeO}^{-}$predominate at $\mathrm{pH}$ around, below and above 6 , respectively. The isoelectric point of chalcopyrite falls at a $\mathrm{pH}$ of about 6.5 , whence the sites $\cdots \mathrm{CuOH}, \cdots \mathrm{CuOH}_{2}^{+}$and $\cdots \mathrm{CuO}^{-}$predominate at $\mathrm{pHs}$ around, below and above 7 , respectively. Consequently, the fixation of ethyl xanthate to their surfaces may be schematically represented as follows:

$$
\begin{aligned}
& \cdots \cdot \mathrm{FeOH}_{2}^{+}+\mathrm{ROCSS}^{-}=\cdots \mathrm{FeOH}_{2} \cdot \mathrm{SSCOR} \\
& \text { (pH 4-8), } \\
& \cdots \cdot \mathrm{FeOH}+\mathrm{ROCSS}^{-}=\cdots \cdot \mathrm{FeOH} \cdot \mathrm{SSCOR}^{-} \\
& \text {(pH 5-8), } \\
& \cdots \mathrm{CuOH}_{2}^{+}+\mathrm{ROCSS}^{-}=\cdots \mathrm{CuOH}_{2} \cdot \mathrm{SSCOR} \\
& \text { (pH 4-6), } \\
& \cdots \mathrm{CuOH}+\mathrm{ROCSS}^{-}=\cdots \mathrm{CuOH} \cdot \mathrm{SSCOR}^{-} \\
& \text {(pH 5-7). }
\end{aligned}
$$

The results of study of the influence of $\mathrm{HCl}$, $\mathrm{H}_{2} \mathrm{SO}_{4}, \mathrm{HNO}_{3}$ and $\mathrm{HF}$ acids on sulphide minerals tested are shown in Fig. 3. Of these acids, $\mathrm{H}_{2} \mathrm{SO}_{4}$ and $\mathrm{HF}$ selectively leach copper sites from the surface of chalcopyrite crystalline lattice due to the relatively great solubilities of copper sulphate and copper fluoride compared with those of iron ${ }^{(22)(25)}$. Of course, it is economically advisable to use $\mathrm{H}_{2} \mathrm{SO}_{4}$. Thus, the treatment of chalcopyrite with $\mathrm{H}_{2} \mathrm{SO}_{4}$ solution of $\mathrm{pH} 3$ effects selective scrubbing of its surface cations which form part of the crystal lattice. This modifies the reactivity of chalcopyrite with ethyl xanthate. Thus, owing to the chemical composition of both molybdenite and pyrite from one type of cations, namely, molybdenum and iron, respectively, chalcopyrite reacts chemically with a $\mathrm{H}_{2} \mathrm{SO}_{4}$ solution resulting in the formation of a new chemically less active surface which disproves the reaction with ethyl xanthate (Fig. 5) and slows its adsorbability and floatability (Fig. 6). This seems to be due to the predominance of ferrous sites which do not form insoluble compounds with ethyl xanthate ${ }^{(23)}$.

It has been reported ${ }^{(23)(27) \sim(32)}$ that the xanthate ion interacts chemically with the oxidised films on the surface of sulphide minerals, forming heavy metal xanthogenates; by this manner of attachment this surface is made hydrophobic. With the unoxidized sulphides there can be an interaction only by the collectors with very high chemical activityhigher mercaptides and disubstituted dithio-

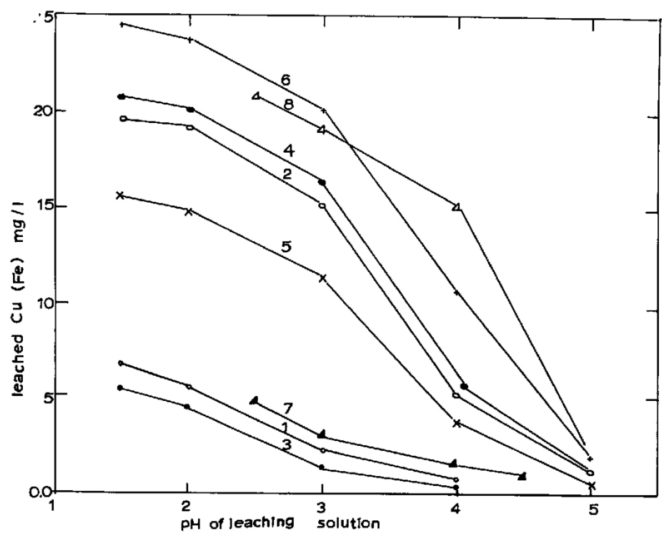

Fig. 3 Influence of $\mathrm{HCl}(1 \& 2), \mathrm{H}_{2} \mathrm{SO}_{4}(3 \& 4), \mathrm{HNO}_{3}$ (5\&6) and $\mathrm{HF}(7 \& 8)$ on the leaching of iron sites (curves odd no) and copper sites (curves even no) from chalcopyrite crystalline lattice surface. 
carbamates $^{(33)(34)}$. A necessary condition for the interaction of the ordinary collectors with sulphide minerals surfaces is preliminary oxidation of the minerals, beginning at the site itself: in storing and grinding the ores, i.e. xanthogenate has still not been introduced to the pulp ${ }^{(35)}$. The difficulty of obtaining an unoxidized sulphide surface is well known ${ }^{(30)}$. The presence of oxidized films is unavoidable when ore is floated under industrial conditions and xanthate should react with them. According to Plaksin and others ${ }^{(34) \sim(36)}$, oxygen is very rapidly sorbed by sulphides and makes the sulphide surface, to some degree, hydrophobic; they consider the action of oxygen as a kind of activation, useful when flotation is carried out with conventional collectors. However, this is not consistent with the results of the same author (Plaksin) who suggests that chalcopyrite is oxidized after 20 or $60 \mathrm{~min}$ of contact with water (Fig. 4). These examples show the contradictions which exist not only between the positions advanced by different authors but also between those suggested by the same author on one hand and flotation

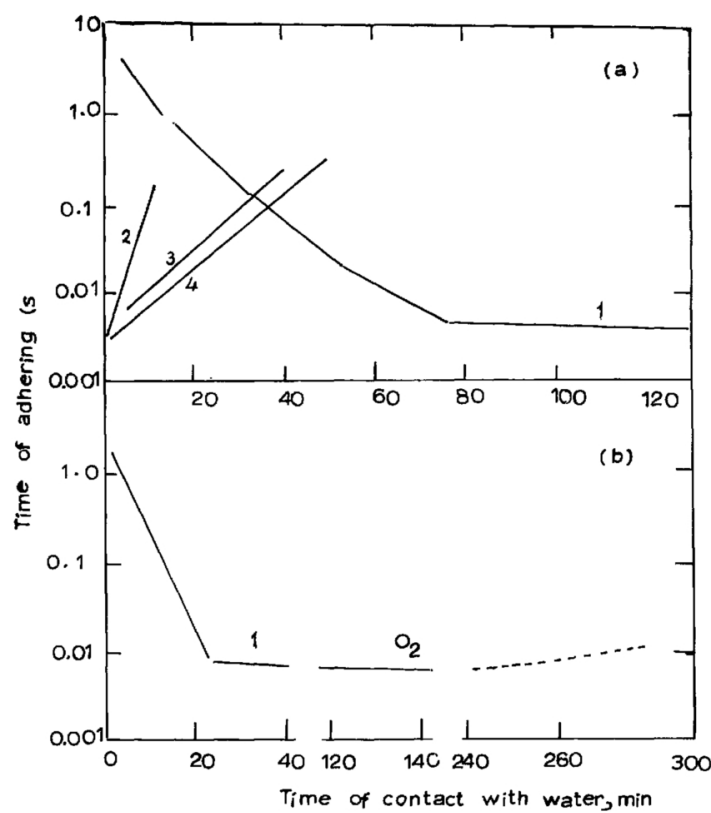

Fig. 4 Change of adhering time to air bubbles of:

(1) chalcopyrite, (2) galena crushed in water, (3) galena miled in air for $1 \mathrm{~min}$, (4) oxidized galena and beforehand sulphidized (After Plaksin(18)(29)).

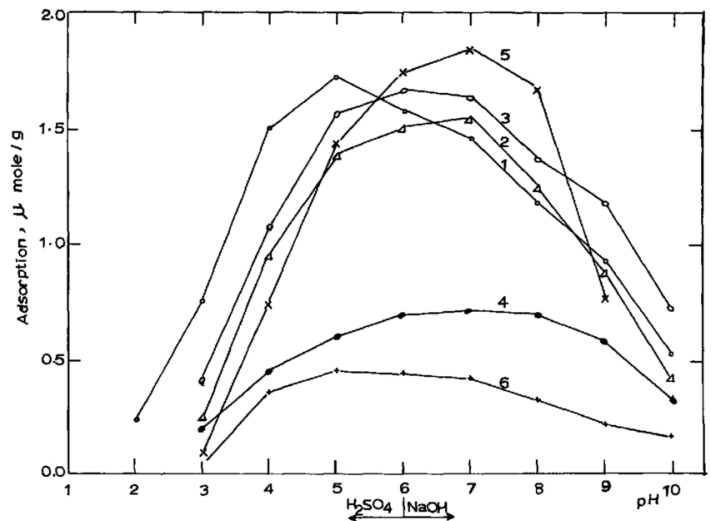

Fig. 5 Exttaction of ethyl xanthate from solution (30 mg/e) by: (1) molybdenite, (2) chalcopyrite, (3) $\mathrm{H}_{2} \mathrm{SO}_{4}$-leached chalcopyrite, (4) $\mathrm{H}_{2} \mathrm{SO}_{4}$-leached chalcopyrite with excess acess of oxygen during adsorption, (5) pyrite, (6) pyrite with excess acess of oxygen during adsorption. N.B. Oxygen was almost without effect on the adsorptive capacities of both molybdenite and chalcopyrite.

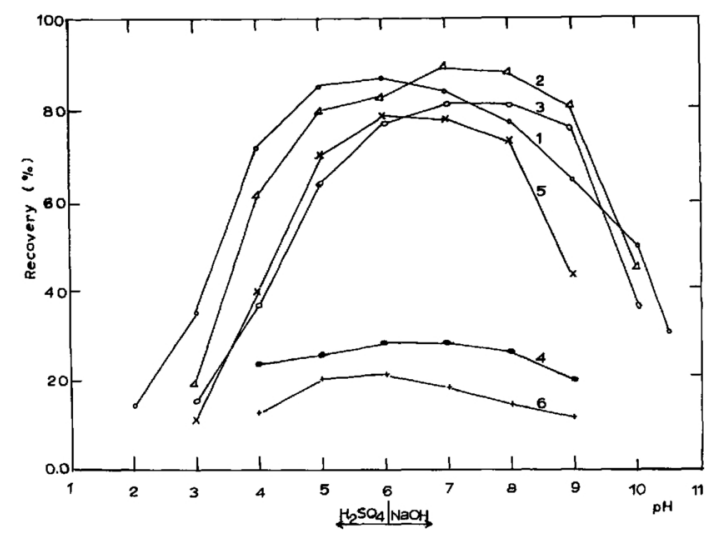

Fig. 6 Recovery of minerals by ethyl xanthate (30 mg/ $)$ : (1) molybdenite, (2) chalcopyrite, (3) $\mathrm{H}_{2} \mathrm{SO}_{4}$-leached chalcopyrite, (4) $\mathrm{H}_{2} \mathrm{SO}_{4}$-leached chalcopyrite with excess acess of oxygen during flotation, (5) pyrite, (6) pyrite with excess acess of oxygen during flotation. N.B. oxygen had little effect on the floatabilities of molybdenite and chalcopyrite.

practice on the other. According to the previously mentioned ideas expressed by different investigators an estimate cannot be made of how much time is required to activate or to deactivate a sulphide mineral. It is also completely unclear how it is possible to effect activation with oxygen if one agrees that it 


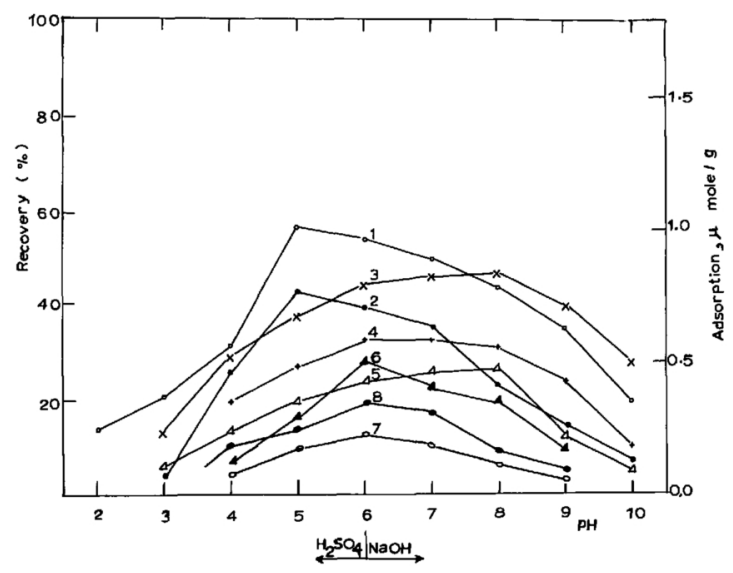

Fig. 7 Influence of $0.01 \%$ solution of $\mathrm{H}_{2} \mathrm{O}_{2}$ on adsorbabilities and floatabilities of (1\&2) molybdenite, (3\&4) chalcopyrite, (5\&6) $\mathrm{H}_{2} \mathrm{SO}_{4}$-leached chalcopyrite, and (7\&8) pyrite: odd numbers represent flotation and even numbers represent adsorption.

is difficult to obtain an unoxidized sulphide surface $^{(10) \sim(21)(30)}$ and that the oxidation of a monolayer of the latter takes only a fraction of a minute or even a fraction of a second ${ }^{(27) \sim(30)}$. In contrast, X-ray structural studies of molybdenite particles showed the absence of any films of oxidized molybdenum compounds on the surfaces of molybdenite particles $^{(26)}$. If one agrees with these findings one would have had to state that aeration (oxygen) is a good and effective regulator during the selective separation of molybdenite from other sulphide minerals such as chalcopyrite and pyrite which is impossible. Indeed, experimention with oxygen and hydrogen peroxide (Figs. 5-7) showed that the former does not play any role in the flotation of sulphide minerals except those of iron due to the easiness of aerial oxidation of ferrous sites to ferric and not due to the oxidation of sulphide sites to sulphate as claim the majority of investigators $^{(10) \sim(23)(27) \sim(36)}$. This is supported by the solubility of ferrous xanthate and the insolubility of ferric xanthate and the decomposition of the latter by oxygen ${ }^{(23)}$. Also, the suggestion of some investigators ${ }^{(26)}$ that slowing down of flotation of copper sulphides and molybdenite, especially during recleaning operations, was connected with the high flotation activity of pyrite-intensifying with a drop in $\mathrm{pH}$ and a reduction of aeration contradicts the suggestion of other investigators ${ }^{(37)}$ that $\mathrm{H}_{2} \mathrm{SO}_{4}$ is used for activation of pyrite by renewing its sulphide surface by dissolving the oxidized inhibiting coating from the surface. However, the tremendous affinity of iron sites for hydroxyl ions coupled with the acidity of ferric hydroxide which is insoluble in an acid medium of $\mathrm{pH} 3.7^{(38)}$, seems to be responsible for the increase of floatoactivity of pyrite with decreasing $\mathrm{pH}$. Consequently, the selective separation of molybdenite from chalcopyrite and pyrite necessitates the use of a regulator.

A new method ${ }^{(39)}$ is proposed for depressing various sulphides by conjoint use of $\mathrm{CuSO}_{4}$ and $\mathrm{Na}_{2} \mathrm{SO}_{3}$. In this investigation an attempt was made to investigate the optimum conditions and mechanism of selective depression of chalcopyrite and pyrite from molybdenite by the reagent mixture $\mathrm{CuSO}_{4}$ and $\mathrm{Na}_{2} \mathrm{SO}_{3}$. The regulating action of sodium sulphite, copper sulphate and their mixture $(0.1 \mathrm{mM} / \ell$ of $\mathrm{Na}_{2} \mathrm{SO}_{3} \cdot 7 \mathrm{H}_{2} \mathrm{O}+0.1 \mathrm{mM} / \ell$ of $\mathrm{CuSO}_{4}$. $5 \mathrm{H}_{2} \mathrm{O}$ ), i.e. $25 \mathrm{mg} / \ell$ of $\mathrm{Na}_{2} \mathrm{SO}_{3} \cdot 7 \mathrm{H}_{2} \mathrm{O}+25$ $\mathrm{mg} / \ell$ of $\mathrm{CuSO}_{4} \cdot 5 \mathrm{H}_{2} \mathrm{O}$ in th eselective flotation of molybdenite was investigated. The results obtained are graphically illustrated in Figs. $8-11$. It is noted that copper sulphate activates the floatabilities of all the minerals in the $\mathrm{pH}$ range 5.5-7.5. Owing to the predominance of $\mathrm{CuOH}^{+}$species in the $\mathrm{pH}$ range $5-8^{(38)}$, the activating action of $\mathrm{CuSO}_{4}$ seems to be due to the following mechanism:

$$
\begin{aligned}
& \cdots \mathrm{Fe}^{\prime \prime} \mathrm{OH}+\mathrm{CuOH}^{+}=\cdots \cdot \mathrm{Fe}^{\prime \prime} \mathrm{OH} \cdot \mathrm{CuOH}^{+} \\
& \text {(pH 5.5-7.5), } \\
& \cdots \mathrm{FeOH} \cdot \mathrm{CuOH}^{+}+\mathrm{ROCSS}^{-} \\
& =\cdots \mathrm{FeOH} \cdot \mathrm{CuOHSSCOR} \\
& \text { (pH 5.5-7.5), } \\
& \cdots \mathrm{FeO}^{-}+\mathrm{CuOH}^{+}=\cdots \mathrm{Fe}^{\prime \prime} \mathrm{O} \cdot \mathrm{HOCu} \\
& \text { (pH 6-7.5), } \\
& \cdots \mathrm{FeO} \cdot \mathrm{HOCu}+\mathrm{ROCSS}^{-} \\
& =\cdots \mathrm{FeO} \cdot \mathrm{HOCu} \cdot \mathrm{SSCOR}^{-} \\
& \text {(pH 6-7.5). }
\end{aligned}
$$

Thus, $\mathrm{CuSO}_{4}$ creates new suitable active sites which form insoluble hydrophobic compounds with ethyl xanthate instead of ferrous sites which do not form such compounds ${ }^{(23)}$. In 


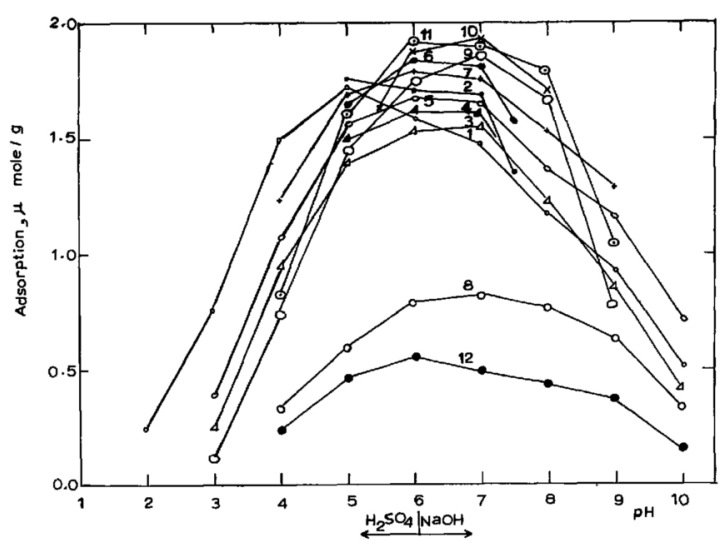

Fig. 8 Influence of $\mathrm{Na}_{2} \mathrm{SO}_{3} \cdot 7 \mathrm{H}_{2} \mathrm{O}$ and $\mathrm{CuSO}_{4}$. $5 \mathrm{H}_{2} \mathrm{O}$ on adsorptive capacities of mineral for ethyl xanthate $(30 \mathrm{mg} / \ell)$ : (1) molybdenite without additions, (2) on addition of $0.1 \mathrm{mM} / \ell$ (i.e. $25 \mathrm{mg} / \ell$ ) or $\mathrm{CuSO}_{4} \cdot 5 \mathrm{H}_{2} \mathrm{O}$, (3) chalcopyrite without additions, (4) on addition of $0.1 \mathrm{mM} / \ell$ (i.e. $25 \mathrm{mg} / \ell$ ) of $\mathrm{CuSO}_{4}$. $5 \mathrm{H}_{2} \mathrm{O}$, (5) $\mathrm{H}_{2} \mathrm{SO}_{4}$-leached chalcopyrite without additions, (6) on addition of $0.1 \mathrm{mM} / \ell$ (i.e. $25 \mathrm{mg} / \ell$ ) of $\mathrm{CuSO}_{4} \cdot 5 \mathrm{H}_{2} \mathrm{O}$, (7) on addition of $0.1 \mathrm{mM} / \ell$ (i.e. $25 \mathrm{mg} / \ell$ ) of $\mathrm{Na}_{2} \mathrm{SO}_{3} \cdot 7 \mathrm{H}_{2} \mathrm{O}$, (8) of $0.2 \mathrm{mM} / \ell$ (i.e. $50 \mathrm{mg} / \ell$ ) of $\mathrm{Na}_{2} \mathrm{SO}_{3} \cdot 7 \mathrm{H}_{2} \mathrm{O}$, (9) pyrite without additions, (10) on addition of $0.1 \mathrm{mM} / \ell$ (i.e. $25 \mathrm{mg} / \ell$ ) of $\mathrm{CuSO}_{4} \cdot 5 \mathrm{H}_{2} \mathrm{O}$, (11) of $0.1 \mathrm{mM} / \ell$ (i.e. $25 \mathrm{mg} / \ell$ ) of $\mathrm{Na}_{2} \mathrm{SO}_{3} \cdot 7 \mathrm{H}_{2} \mathrm{O},(12)$ of $0.2 \mathrm{mM} / \ell$ (i.e. $50 \mathrm{mg} / \ell$ ) of $\mathrm{Na}_{2} \mathrm{SO}_{3} \cdot 7 \mathrm{H}_{2}$ O. N.B. $\mathrm{Na}_{2} \mathrm{SO}_{3} \cdot 7 \mathrm{H}_{2} \mathrm{O}$ had almost no effect on adsorptive capacities of molybdenite and chalcopyrite.

the case of aerial oxidation of ferrous sites to ferric, the latter could form insoluble hydrophobic compounds with ethyl xanthate, which are decomposed by further action of oxygen. The suggestion of Gaudin ${ }^{(23)}$ and Mitrofanov $^{(26)(27)}$ that pure (unoxidized) pyrite responds well to xanthate flotation is in complete opposition to Gaudin's hypothesis that ferrous iron do not form stable insoluble salts with xanthates and that ferric xanthate is decomposed by oxidation. Similarly, the suggestion of Mitrofanov ${ }^{(26)}$ that the flotation activity of pyrite is so great that under certain conditions a considerable portion of it could be selectively separated from copper sulphide minerals and molybdenite is not in agreement with his suggestion that sulphide minerals are readily (within a fraction of a second) oxidized by aerial oxygen and that the presence of an oxidized film on their surfaces is inevita$\mathrm{ble}^{(27)(40)(41)}$.

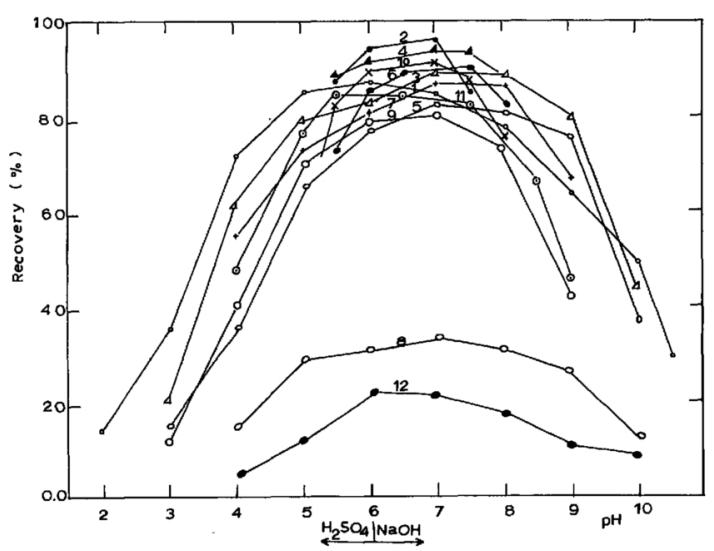

Fig. 9 Recovery of minerals in flotation with ethyl xanthate $(30 \mathrm{mg} / \ell):$ (1) molybdenite without additions, (2) on addition of $0.1 \mathrm{mM} / \ell$ (i.e. $25 \mathrm{mg} / \ell$ ) of $\mathrm{CuSO}_{4} \cdot 5 \mathrm{H}_{2} \mathrm{O}$, (3) chalcopyrite without additions, (4) on addition of $0.1 \mathrm{mM} / \ell$ (i.e. $25 \mathrm{mg} / \ell$ ) of $\mathrm{CuSO}_{4}$. $5 \mathrm{H}_{2} \mathrm{O}$, (5) $\mathrm{H}_{2} \mathrm{SO}_{4}$-leached chalcopyrite without additions, (6) on addition of $0.1 \mathrm{mM} / \ell$ (i.e. $25 \mathrm{mg} / \ell$ ) of $\mathrm{CuSO}_{4} \cdot 5 \mathrm{H}_{2} \mathrm{O}$, (7) on addition of $0.1 \mathrm{mM} / \ell$ of $\mathrm{Na}_{2} \mathrm{SO}_{3} \cdot 7 \mathrm{H}_{2} \mathrm{O}$ (i.e. $25 \mathrm{mg} / \ell$ ), (8) of $0.2 \mathrm{mM} / \ell$ (i.e. $50 \mathrm{mg} / \ell$ ) of $\mathrm{Na}_{2} \mathrm{SO}_{3} \cdot 7 \mathrm{H}_{2} \mathrm{O}$, (9) pyrite without additions, $(10)$ on addition of $0.1 \mathrm{mM} / \ell$ (i.e. $25 \mathrm{mg} / \ell$ ) of $\mathrm{CuSO}_{4} \cdot 5 \mathrm{H}_{2} \mathrm{O}$, (11) of $0.1 \mathrm{mM} / \ell$ (i.e. $25 \mathrm{mg} / \ell$ ) of $\mathrm{Na}_{2} \mathrm{SO}_{3} \cdot 7 \mathrm{H}_{2} \mathrm{O},(12)$ of $0.2 \mathrm{mM} / \ell$ (i.e. $50 \mathrm{mg} / \ell$ ) of $\mathrm{Na}_{2} \mathrm{SO}_{3} \cdot 7 \mathrm{H}_{2} \mathrm{O}$. N.B. $\mathrm{Na}_{2} \mathrm{SO}_{3} \cdot 7 \mathrm{H}_{2} \mathrm{O}$ showed almost no perceptible effect on floatabilities of molybdenite and chalcopyrite.

$\mathrm{Na}_{2} \mathrm{SO}_{3}$ by itself had no effect on adsorbabilities and floatabilities of either molybdenite or chalcopyrite but did promote adsorptive capacities and floatoactivities of both pyrite and $\mathrm{H}_{2} \mathrm{SO}_{4}$-leached chalcopyrite (Figs. 8 and 9). This seems to be due to the great affinity of sodium sulphite for oxygen which favors the existence of ferric xanthate. On the other hand, when $\mathrm{Na}_{2} \mathrm{SO}_{3}$ is added in too a great quantity (Figs. 8 and 9) the flotation of both pyrite and $\mathrm{H}_{2} \mathrm{SO}_{4}$-leached chalcopyrite is inhibited due probably to the unoxidation of ferrous sites to the ferric which could bind the collector.

Experimentation with the reagent mixture $\left(0.1 \mathrm{mM} / \ell\right.$ of $\mathrm{Na}_{2} \mathrm{SO}_{3} \cdot 7 \mathrm{H}_{2} \mathrm{O}+0.1 \mathrm{mM} / \ell$ of $\mathrm{CuSO}_{4} \cdot 5 \mathrm{H}_{2} \mathrm{O}$ ), (i.e. $25 \mathrm{mg} / \ell$ of $\mathrm{Na}_{2} \mathrm{SO}_{3}$. $7 \mathrm{H}_{2} \mathrm{O}+25 \mathrm{mg} / \ell$ of $\mathrm{CuSO}_{4} \cdot 5 \mathrm{H}_{2} \mathrm{O}$ ) showed that it is almost without effect on the adsorptive and floatative properties of molybdenite and chalcopyrite but deactivates adsorbabilities and floatabilities of pyrite and $\mathrm{H}_{2} \mathrm{SO}_{4}$-leached chalcopyrite. This indicates that the suggestion 


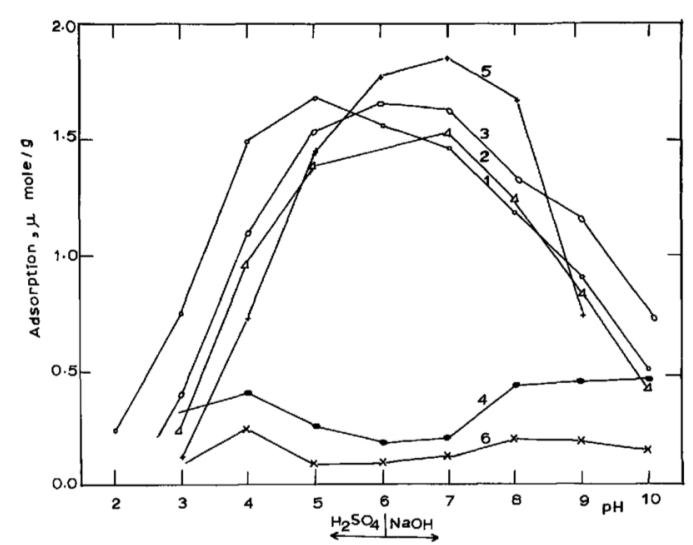

Fig. 10 Influence of combination of $\mathrm{CuSO}_{4} \cdot 5 \mathrm{H}_{2} \mathrm{O}$ and $\mathrm{Na}_{2} \mathrm{SO}_{3} \cdot 7 \mathrm{H}_{2} \mathrm{O}$ on sorption of ethyl xanthate $(30 \mathrm{mg} / \ell)$ by the minerals: (1) molybdenite without additions, (2) chalcopyrite, (3) $\mathrm{H}_{2} \mathrm{SO}_{4}$-leached chalcopyrite without additions, (4) on addition of the reagent mixture $0.1 \mathrm{mM} / \ell$ (i.e. $25 \mathrm{mg} / \ell$ ) of $\mathrm{CuSO}_{4} \cdot 5 \mathrm{H}_{2} \mathrm{O}+0.1 \mathrm{mM} / \ell$ (i.e. $25 \mathrm{mg} / \ell$ ) of $\mathrm{Na}_{2} \mathrm{SO}_{3}$. $7 \mathrm{H}_{2} \mathrm{O}$, (5) pyrite, (6) on addition of the reagent mixture. N.B. The reagent mixture was almost without effect on extraction of ethyl xanthate by molybdenite and chalcopyrite from solution.

of Konev ${ }^{(39)}$ that the reagent mixture depresses various sulphide minerals except molybdenite is, however, partly incorrect since each sulphide mineral requires somewhat different conditions for its depression. For example, chalcopyrite responds well to ethyl xanthate flotation in the presence of this reagent mixture, whereas $\mathrm{H}_{2} \mathrm{SO}_{4}$-leached chalcopyrite does not (Figs. 10 and 11). The available data in the literature $^{(42)(43)}$ indicate that copper sulphate forms with sodium sulphite a complex anion of the type $\mathrm{CuSO}_{4} \mathrm{SO}_{3}^{2-}$. Owing to the occurrence of the isoelectric points of molybdenum and iron sites around $\mathrm{pHs}$ of 5 and 6.5-8.5, respectively ${ }^{(44)(45)}$ the complex copper sulphate sulphite anion is attached preferably to the positively charged iron sites:

$$
\begin{aligned}
\cdots \mathrm{Fe}^{\prime \prime} \mathrm{OH}+\mathrm{CuSO}_{4} \mathrm{SO}_{3}^{2-} & \\
& =\cdots \mathrm{FeOH} \cdot \mathrm{CuSO}_{4} \mathrm{SO}_{3}^{-} \\
& (\mathrm{pH} 5-6.5) .
\end{aligned}
$$

The fall of $\mathrm{pK}_{a}$ of xanthic acid at a $\mathrm{pH}$ of $5^{(22)}$, which is near from the $\mathrm{pH}$ of isoelectric point of molybdenite surface seems to be responsible for maximal adsorbability and floatability of molybdenite at $\mathrm{pH}$ of 5 . Indeed, Frumkin and

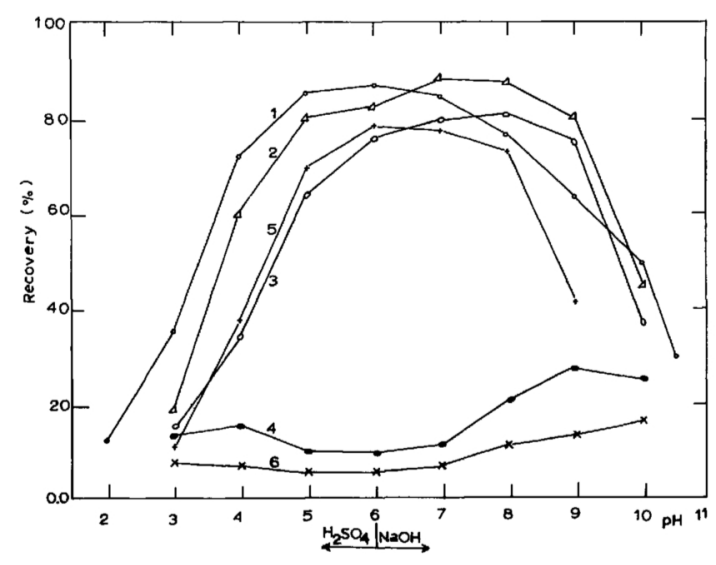

Fig. 11 Influence of combination of $\mathrm{CuSO}_{4} \cdot 5 \mathrm{H}_{2} \mathrm{O}$ and $\mathrm{Na}_{2} \mathrm{SO}_{3} \cdot 7 \mathrm{H}_{2} \mathrm{O}$ on floatabilities of minerals with ethyl xanthate $(30 \mathrm{mg} / \ell):(1)$ molybdenite, (2) chalcopyrite, (3) $\mathrm{H}_{2} \mathrm{SO}_{4}$-leached chalcopyrite without additions, (4) on addition of the reagent mixture $0.1 \mathrm{mM} / \ell$ (i.e. $25 \mathrm{mg} / \ell$ ) of both $\mathrm{CuSO}_{4}$. $5 \mathrm{H}_{2} \mathrm{O}$ and $\mathrm{Na}_{2} \mathrm{SO}_{3} \cdot 7 \mathrm{H}_{2} \mathrm{O}$, (5) pyrite, (6) pyrite on addition of the reagent mixture $0.1 \mathrm{mM} / \ell$ (i.e. $25 \mathrm{mg} / \ell$ ) of both $\mathrm{CuSO}_{4} \cdot 5 \mathrm{H}_{2} \mathrm{O}$ and $\mathrm{Na}_{2} \mathrm{SO}_{3} \cdot 7 \mathrm{H}_{2} \mathrm{O}$. N.B. The reagent mixture showed almost no perceptible effect on floatabilities of molybdenite and chalcopyrite.

Geld $^{(46) \sim(49)}$ claim that optimum conditions are created for molecular sorption of collector by a reduction in surface charge of the mineral and by its approach to zero value. Although there is a sharp increase in the adsorption of the collector molecules accompanied by a sharp growth in molybdenite flotation, there is no perceptible change in its zeta potential (Figs. 2, 10 and 11). The attachment of xanthic acid to molybdenite surface may be represented schematically as follows:

$$
\begin{array}{r}
\cdots \mathrm{MoS}+\mathrm{ROCSSH}=\cdots \mathrm{MoS} \cdot \mathrm{HSSCOR} \\
(\mathrm{pH} \sim 5) .
\end{array}
$$

Thus, the selective ethyl xanthate flotation of the molybdeinte from pyrite and chalcopyrite seems quite feasible after leaching the latter with solution of $\mathrm{H}_{2} \mathrm{SO}_{4}$ of $\mathrm{pH} 3$ and an addition of a mixture of $0.1 \mathrm{mM} / \ell$ (i.e. $25 \mathrm{mg} / \ell$ ) of $\mathrm{Na}_{2} \mathrm{SO}_{3} \cdot 7 \mathrm{H}_{2} \mathrm{O}+0.1 \mathrm{mM} / \ell$ (i.e. $25 \mathrm{mg} / \ell$ ) of $\mathrm{CuSO}_{4} \cdot 5 \mathrm{H}_{2} \mathrm{O}$.

\section{Conclusions}

Ideas expressed by investigators about the 
role and the mechanism of oxygen (aeration) in the selective flotation of molybdenite from other sulphide minerals such as chalcopyrite and pyrite are very speculative. Some investigators claim that molybdenite is resistant to oxidation and that X-ray structural studies showed the absence of any oxidized films on surfaces of molybdenite particles, whereas the majority of investigators confirm that sulphide minerals are readily (within a fraction of a second) oxidized by aerial oxygen and that the presence of an oxidized film on their surfaces is inevitable. Furthermore, the investigators who suggest that preliminary oxidation of surfaces of sulphide minerals is necessary for fixation of xanthate and successful flotation claim that pure (unoxidized) pyrite responds well to xanthate flotation. However, the results of this investigation showed that sulphide sites in crystalline lattice surfaces of sulphide minerals are resistant to oxidation and that their preliminary oxidation inhibits rather than promotes flotation. The activating action of oxygen on pyrite flotation was shown to be due to the oxidation of ferrous sites which do not form insoluble xanthates to ferric which form, and not due to oxidation of sulphide sites to sulphate as the majority of investigators claim. The deactivating effect of long action of oxygen on pyrite was shown to be due to the decomposition of ferric xanthate and not due to complete oxidation of sulphide sites to sulphate as most investigators suggest. Owing to crystal structures faces of molybdenite particles are composed exclusively of sulphide sites, whereas those of chalcopyrite and pyrite are composed of alternate cations (copper and/or iron) and sulphide sites. This coupled with the occurrence of the isoelectric point of molybdenite at a $\mathrm{pH}$ close to that of the $\mathrm{pK}_{a}$ of xanthic acid creates suitable conditions for the attachment of the latter to surfaces of molybdenite particles in sufficient quantity for its selective flotation to take place. The feasibility of selective leaching of copper sites by a solution of $\mathrm{H}_{2} \mathrm{SO}_{4}$ of $\mathrm{pH} 3$ from surface of crystalline lattice of chalcopyrite and the fall of the isoelectric point of iron site at $\mathrm{pH}$ higher than 6.5 inhibit the attachment of collector molecules to pyrite and $\mathrm{H}_{2} \mathrm{SO}_{4}$ - leached chalcopyrite surfaces. In contrast, the complex hydrophilic anion $\mathrm{CuSO}_{4} \mathrm{SO}_{3}^{2-}$ resulting from the combination of sodium sulphite and copper sulphate possesses a tremendous affinity for the positively charged iron sites over molybdenum in the range of $\mathrm{pH} 5$ to 6.5 leading to selective depression of pyrite and $\mathrm{H}_{2} \mathrm{SO}_{4}$-leached chalcopyrite from molybdenite.

\section{REFERENCES}

(1) S. I. Mitrofanov and A. V. Kurochkina: Some probleme connected with the flotation of molybdenite from copper-molybdenum ores, collections Gintsvetmet, (10) (1955).

(2) V. K. Apollonov: Extracting Molybdenum from the Bulgarian concentration plant Rossen No. 1. TsIIN Ts, (16) (1960) 165.

(3) I. N. Plaksin, A. E. Cunelnikova and G. N. Xaginskia: Role of Gases and the Use of Oxygen in Flotation, Trans. Academic Science USSR, (1952).

(4) I. N. Plaksin, A. E. Okalavitch, B. B. Schikova and G. M. Dmetriva: About the Question of the Methods of Flotation of Polysulphides, Tsvetni Metalli, 11 (1956).

(5) I. N. Plaksin and E. A. Ankimov: Trans. ANUSSR (Academic Science of USSR), (10) (1954), p. 123.

(6) A. M. Caudin and D. W. Fuerstenau: Trans. AIME, 202 (1956). 66.

(7) Handbook of Chemistry and Physics, A ready reference book of Chemical and Physical data, 52nd edn Robert C. W. ed., published by the Chemical Rubber Co., Cranwood Parkways, Cleveland, Ohio, (1971-1972), P. D-227, E-43-50, F-71.

(8) Handbook of Chemistry, 2nd Ed. Lange N. A. and Forker G. M. eds. Sendusky, Ohio, Handbook Publishers, (1937), P. 1160.

(9) A. M. Abeidu: J. Less-Common Metals, 22 (1970) 335.

(10) S. M. Essiokivitch, P. M. Sologenkin: Sov. J. Non-Ferrous Metals, 11 (1957), (in Russian).

(11) V. A. Glembotskii, V. I. Klassen and I. N. Plaksin: Flotation, "Gosgortekhizdat," Moscow, (1961), p. 75 (in Russian).

(12) I. N. Plaksin, S. V. Bessobov and I. R. Solov'iova : Collection Trudy AN SSSR, 11 (1955), p. 742 (in Russian).

(13) I. N. Plaksin, A. E. Sinellnikova and G. N. Xaginskaia: Izdatelstva AN SSSR, (1952), p. 813 (in Russian).

(14) S. V. Bessonov and I. N. Plaksin: Izv. AN SSSR, OTN no. 1, January, (1956), p. 74 (in Russian).

(15) I. N. Plaksin, S. V. Bessonov and I. R. Solovviova: Report of UGD AN, (1953), p. 1 (in Russian).

(16) I. N. Plaksin, S. V. Bessonov, I. R. Solovviova, 
E. M. Tchapleigna, E. L. Rayxvarger and O. V. Tretiakov: Report UGD SSSR, (1954), p. 1 (in Russian).

(17) I. N. Plaksin, S. V. Bessonov and V. E. Tiornikova: DAN SSSR, Vol. 102, No. 2, (1955), p. 164 (in Russian).

(18) I. N. Plaksin and S. V. Bessonov: DAN SSSR, Vol. 97, No. 3, (1954), p. 916 (in Russian).

(19) I. N. Plaksin and S. V. Bessonov: DAN SSSR, Vol. 98, No. 3, (1954), p. 483 (in Russian).

(20) I. N. Plaksin and E. A. Anfimova: Trans. AN SSSR, OTN, (5) (1954), p. 659 (in Russian).

(21) I. N. Plaksin and R. Ch. Chaveiv: DAN SSSR, Vol. 135, No. 1, (1960), p. 141 (in Russian).

(22) K. L. Sutherland and I. W. Wark: Australian Inst. Min. Metall., Melbourne, (1955), 96, 294.

(23) A. M. Gaudin: Flotation, 2nd Ed., New York, London, McGraw-Hill, (1957), p. 203, 204, 233-256, 289, 290.

(24) F. F. Aplan and D. W. Fuerstenau: Eroth flotation-50 Anniversary Volume, AIMME, New York, (1962), p. 81-138.

(25) A. Siedell: Solubilities of Inorganic and Metal Organic Compounds. A Compilation of Quantitative Solubility Data from the Periodical Literature, vol. 1, 1940, 3rd edn, 3rd Printing, New York, D. Van Nostrand Co., INC, p. 521-546.

(26) S. I. Mitrovanov and A. V. Kurochkina: Sov. J. Non-Ferr. Metals, 5(10) (1964) 4, (Eng. Trans.).

(27) S. I. Mitrovanov: Selective flotation, Metallurgizdat, (1958).

(28) E. J. Pryor: Mineral Processing, 3rd edn, Elsevier Publishing Co. Ltd., Amsterdam, London, New York, (1965), p. 495-497.

(29) I. N. Plaksin and S. V. Bessonov: DAN SSSR, Vol. 61, No. 5, (1948), p. 969 (in Russian).

(30) I. A. Kakovskii: Izd., AN SSSR, (1950), p. 397 (in Russian).

(31) I. N. Shorsher: Flotation of Carbonate Minerals, Izd. Inst. Mekhaobr, Issue 104, (1957), (in Russian).

(32) O. S. Bogdanov, A. K. Podnek, V. Ya. Khainman and N. A. Yanis: Problems Connected with the Theory and Technology of Flotation, Trudy Mekhanobr, Leningrad, issue 124, (1959), (in
Russian).

(33) I. A. Kakovskii, E. I. Silina and A. N. Grebnev: Izv. Vuzov, Tsvetnaya Metallurgia, 5(3) (1962) 42-48 and (4) 33-45, (in Russian).

(34) I. N. Plaksin and S. V. Bessonov: Izv. AN SSSR, OTN, (1948), No. 11, 1773-1788; (1954); No. 1, 114-127, (in Russian).

(35) I. A. Kakovskii and V. M. Arashkevich: Sov. J. Non-Ferr. Metals, 4(6) (1963) 10, (Eng. Trans.).

(36) I. N. Plaksin: Izd. AN SSSR, (1950), p. 109 (in Russian).

(37) R. H. Richards and C. E. Locke: Text Book of Ore Dressing, 3rd Ed., McGraw-Hill Book Company, Inc. New York and London, (1953), p. 247.

(38) R. B. Fisher and D. G. Petters: Basic Theory and Practice of Quantitative Chemical Analysis, 3rd edn, W. B. Saunders Co., Philadelphia, London, Toronto, (1968), p. 380, 588.

(39) L. A. Koneva: Obagachenia rud, 3(63) (1966), 9-12, (in Russian).

(40) S. I. Mitrofanov and V. G. Kusnikova: Trans. Intern. Minetal Dressing Congress, Stockholm; 1957, Almqvist and Wiksell, Stockholm, (1958), p. 461.

(41) S. I. Mitrovanov: ibid., p. 441.

(42) J. W. Mellor: A Comprehensive Treatise in Inorganis and Theoritical Chemistry, Longmans, Green and Co., London, New York, Toronto, Vol. 3, (1947).

(43) V. A. Konev: Sov. J. Non-Ferr. Metals, (7) (1966) 8, (in Russian).

(44) J. Iwasaki, R. S. Cook and H. S. Choi: Trans. Met. Soc. AIME, 217 (1960) 237.

(45) P. L. DeBruyn and G. E. Agar: Froth Flotation50th Anniversary Volume, New York, AIMME, (1962), 91-138.

(46) A. N. Frumkin: Kinetics of Selective Processes, MGU Publications, (1952) ,p. 732 (in Russian).

(47) N. A. Geld: Collection, Proc. of Research Sector of Mekhanobr Institute, Leningrad, Vol. 1, (1935), p. 136 (in Russian).

(48) N. A. Geld and K. N. Samokhvalov: DAN SSSR, (5) (1934) 263, (in Russian). 